\title{
"Socio economic, Demographic and Geographic Influence on Disease Activity of Bronchial Asthma in Kashmir Valley"
}

\author{
${ }^{1}$ Arif Habib, ${ }^{1}$ S. Jamil, ${ }^{2}$ Irfat Ara, ${ }^{3}$ Basharat, ${ }^{3}$ Y. I. Munshi, ${ }^{3}$ Nighat Ara \\ CCRUM, Deptt. of AYUSH Ministry of Health \& Family Welfare, Govt. of India.
}

\begin{abstract}
Zeequn Nafas (Bronchial Asthma) is diffused involvement of bronchial system due to variety of influences resulting in chronic respiratory disability. In other words, it is difficulty in breathing due to narrowing of air passage, particularly in expiration associated with bronchial spasm. It has been identified as one of the five most pressing global lung problems. Buqrat (Hippocrates) (460-377 BC) first studied the effect of climate, water, cloths, drinks, and eating habits and others factors as the causative for the disease. According to him, it was believed to be brought about by an imbalance of humors by raised level of phlegm. He also noted the possibility that asthma could be an inherited condition.

Abu Hassan Ali Gilani believed that asthma was caused by thick viscid humors in the lungs and through that it is resulted from a lack of room in the cavities of the lungs. He thought that it was a more severe form of dyspnoea and prescribed attenuate and detergent medicines, forbidding all things hot or cool, as well as astringents, as these might thicken the humors and tried purging the nostrils. He recommended vinegar and oxymal of quills. Gilani thought that opiates were harmful in the asthma, because they cooled too much and thereby thickened the humors. Ibn-e-Sina (Avicenna, 980-1037 AD) was of the opinion that repeated influence of mисоsal oedema and the excessive bronchial phlegmatic secretions and its inefficient clearance leads to the thickening and hardening of the bronchioles. This leads to obstruction of the airflow.

In modern medicine Zeequn nafas is described under the heading of bronchial asthma. The word Asthma is derived from Greek word meaning short drawn breath, panting or laboured breathing. Zeequn Nafas (Bronchial Asthma) is diffused involvement of bronchial system due to variety of influences resulting in chronic respiratory disability (Colledge, et. al. 2010; Kumar \& Calrk, 2004; Stein, 1998). It has been identified as one of the 5 most pressing global lung problems (Barnes, et. al., 1996). The prevalence of asthma is rising and 5-9\% of general population in India is suffering from Bronchial asthma (Gupta, et. al., 1999).

Kashmir due to its varying climatic conditions and other factors is called to be the house for the respiratory tract disorders. The living habits in rural as well as urban areas are quite different and unique which is significantly responsible for higher incidence of the disease. The climate of Jammu and Kashmir varies greatly owing to its rugged topography. In the south around Jammu, the climate is typically monsoonal, though the region is sufficiently far west to average 40 to $50 \mathrm{~mm}$ (1.6 to 2 inches) of rain per months between January and March. In the hot season, Jammu city is very hot and can reach up to $40{ }^{\circ} \mathrm{C}\left(104{ }^{\circ} \mathrm{F}\right)$ whilst in July and August, very heavy though erratic rainfall occurs with monthly extremes of up to 650 millimetres (25.5 inches). In September, rainfall declines, and by October conditions are hot but extremely dry, with minimal rainfall and temperatures of around $29^{\circ} \mathrm{C}\left(84^{\circ} \mathrm{F}\right)$.
\end{abstract}

Key words:- Bronchial asthma, socio economic status, climatic change, Respiratory morbidity, prevalence, Kashmir valley.

\section{Aim:}

The aim of this study was to determine socio economic status, demographic and geographic influence associated with the disease.

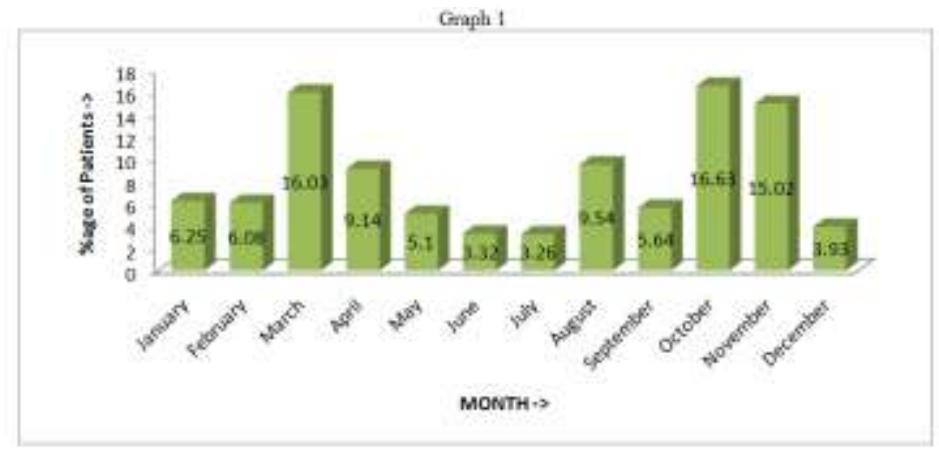


Grant 2

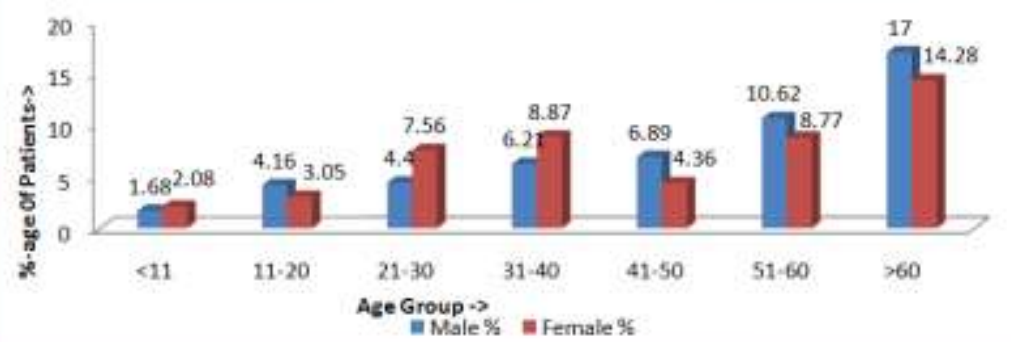

Gronis 3

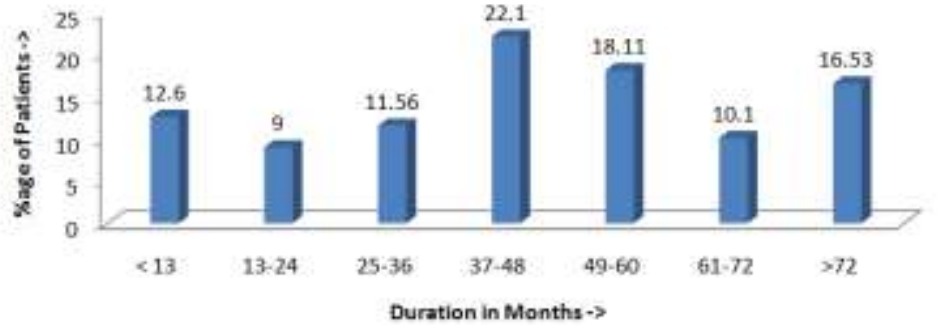

Grank 4

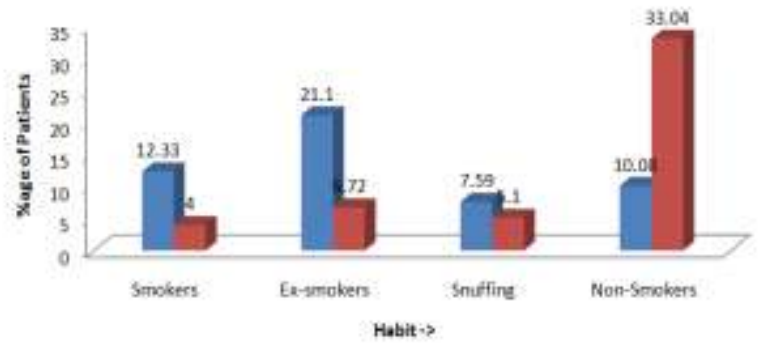

males $=$ Femolef

Graph 5

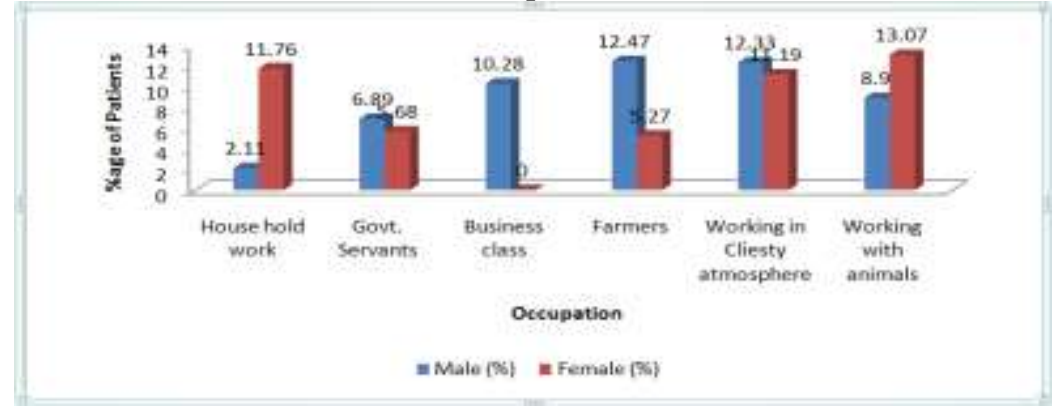

Graph 6 


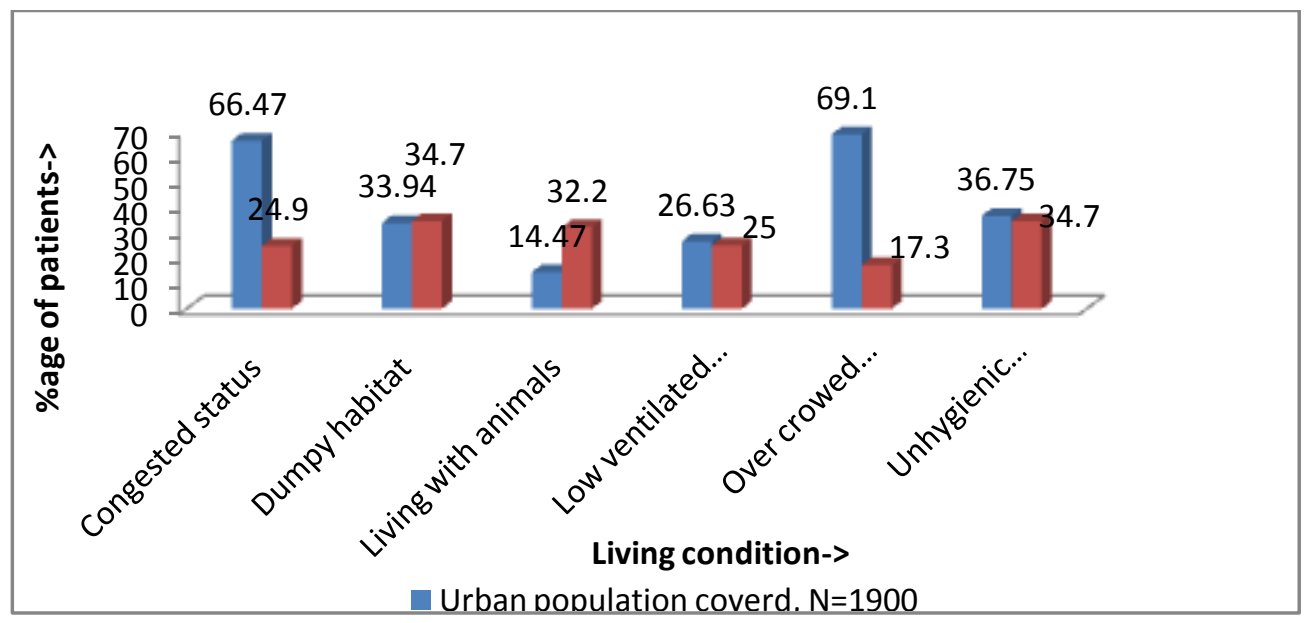

\section{Results and discussion:-}

We managed data using Microsoft Office Excel 2007 and analyzed the data using SPSS (version 20.0) for Windows to calculate the observations taken into consideration. The main demographic groups of interest for this analysis were Kashmiri people. 2975 subjects were registered for the study. 1517 were male and 1458 were female. In the clinical setting, asthma is diagnosed based on history, physical examination, and physiological testing (which most commonly includes, but is not limited to, spirometry and bronchodilator reversibility testing). In population based surveys, time and logistic constraints do not allow the use of most of these modalities. Although the use of a validated questionnaire remains the most popular method for field studies, there can be no strict validation for any test of asthma. Epidemiological studies on prevalence of asthma, therefore, often suffer from a lack of definite criteria for diagnosis of disease and a standardised methodology. Different investigators have used different parameters such as physician-diagnosed asthma, demonstration of variable airflow obstruction, or bronchial hyper reactivity as gold standards for validating questionnaires employed to diagnose asthma under field conditions. Each method has its own limitations of either under-diagnosing or over-diagnosing asthma. A significant proportion of the general population suffers from respiratory symptoms of varied etiology (including asthma), and the greatest problems in any population survey is to correctly identify asthmatics from this subset. Obviously, no epidemiological tool can be a perfect discriminator in this regard with $100 \%$ sensitivity and specificity. The problem of misdiagnosis in questionnaire-based surveys depends not only on the structure and inherent properties of the questionnaire, but also on the social, demographic and medical factors of the population being studied. Any epidemiological study can therefore provide only imprecise estimates of the true burden of disease, although use of better tools can certainly reduce the degree of imprecision. We used a questionnaire validated against physician-diagnosed asthma under out patient department (OPD) in hospital and field conditions.

It was observed that male was showing a slight higher level of occurrence of the disease than female counter parts. The study is very important due to many reasons, One being, that it was made for the first time in valley. Second being, that it covers not only the one but many parameters (conditions) of the people. Kashmir valley is temperate in origin, the level of incidence of Bronchial Asthma were recorded highest in the month of October (16.63\%) fallowed by March (16.03\%) and November (15.02\%) respectively (see graph 1). Since these months witness a change in climatic conditions due to seasonal changes therefore the data was obtained. It was also observed that the disease is directly proportional with the gradual increase of age, (see graph 2). The highest incidence has been recorded in the age group $>60$. The study showed significant relation between the age and disease $(r)=-0.3745$ as the therapy effects showed significant response in the age at $<20$ years and has same relation of onset of disease $95 \%$ confidence interval: -0.7672 to 0.2226 . As evident from the (graph 3) it was observed that the disease may be taken as chronic bronchial asthma, it is therefore that the chronicity of the patients lies in between 1 year to more than 6 years as per data were calculated. The habit of the subjects were also observed and it was found that the incidence of the disease was highest among non smokers fallowed by Ex-smokers (see graph 4). Also males were more prone than females (3:1) in smoking habits. It can be assumed that the smokers have continuous exposure to smoke, this might have developed immunity to smoke allergy as compared to non smokers. So it may be concluded that the non smokers have high incidence of Bronchial Asthma. In the present study it was found that the females are more prone than males working with animals(13.07\%) and house hold work(11.76\%), where as males have high incidence who are working in farms $(12.47 \%)$. The incidence of the disease can be treated same who are working in cliesty atmosphere (see graph 5,6). Social - economic status plays important role with the disease. It was found that the people living in congested and crowded urban areas were more affected, where as in rural areas people living with dumpy 
habitat and unhygienic environment (34.7\%) were more affected with Zeequn nafs (Graph 6, 7). Screening of population randomly selected an overall prevalence rate of $9.7 \%$ for chronic bronchitis and $2.7 \%$ for asthma. This increased prevalence of chronic bronchitis was attributed to exposure to domestic smoke pollution, lower socio-economic status, illiteracy, poor housing conditions and overcrowding.

\section{Conclusion and future prospects:}

Despite certain limitations of our study, we conclude that it is essential to expand health care services and screening programmes for the awareness, diagnosis and treatment of bronchial asthma. The respondents were characterised by certain sociodemographics, patterns of living, smoking habits that were somewhat similar to national and international research. This study lays foundation for future research in asthma in the region of Jammu \& Kashmir and the states having same climatic condition. The present study shows that bronchial asthma is an important public health issue. It also showed that age and the disease is correlated. In order to attain better quality life in a chronic disease condition like bronchial asthma, one needs to be aware of its aggravating factors.

\section{References:}

[1] Barnes, P.J, (1996). Is immunology for Asthma worth while, N Engl. J. Med, 334: 531 -532.

[2] Colledge, N.C.; Walker, B.R.; Ralston, S.H (2010). Davidson's Principles and Practice of Medicine, 21 Edition. Churchill Livingstone, 662-671.

[3] Gupta, K.B.; Tondon, S. (1999). Noctural Asthma, Lung India, vol. 1: 1-5.

[4] Ibne Sina, S. (1906). AlQanoon Fit Tibb, Juz Salis Matba Nami, Pp 217-220.

[5] Kabiruddin, M. (1960). Tarjuma Kabir, part-2, Matba Daftarul Maseeh, Delhi. Pp 557-558.

[6] Khan, H.M.A. (1978). Haziq, Siddiqui Kitab Ghar, Lahore. Pp 137-139.

[7] Khan, M.A. (1289H). Akseer-e-Azam, Matba Nizami Kanpur, Pp 126-128.

[8] Kumar, P.; Clark, M. (2004). Kumar \& Clark Clinical Medicine, 5th Edn. W. B. Saunders, London, 874-884.

[9] Majoosi, A. (2010). Kamil-us-Sana, Vol-1, (Urdu Translation) Idara Kitab Alshifa, Dariya Ganj, Delhi-2. Pp 490-492.

[10] Razi, Z. (1957). Kitab Al Hawi, Part- 4, matba Dairatul Muarif, Usmania Hyderabad 1-2.

[11] Jindal SK, Gupta D, Aggarwal AN, Jindal RC, Singh V.Study of the prevalence of asthma in adults in north India using a standardized field questionnaire. J Asthma 2000: 37.345-51.

[12] Joyce S, Daly A. Health and Wellbeing of Adults in Western Australia 2009, Overview and Trends. Perth: Department of Health, Western Australia; 2010.

[13] National Asthma Education and Prevention Program. Expert Panel Report 3: Guidelines for the Diagnosis and Management of Asthma. NIH Publication 07-4051. Bethesda; 2007(Updated).

[14] World Health Organization (WHO). Epidemiology of chronic non-specific respiratory diseases. Bull WHO 1975; 52: 251 259

[15] Department of Health WA. WA Chronic Health Conditions Framework 2011-2016. Perth: Health Networks Branch, Department of Health WA; 2011.

[16] Kauffmann F, Dizier M-H, Pin I, et al. Epidemiological study of the genetics and environment of asthma, bronchial hyper responsiveness and atopy. Am J Respir Crit Care Med 1997; 156: S123 \pm S129.

[17] Gregg I. Why study the epidemiology of asthma? Thorax 1988; 43: 1024.

[18] De Marco R, Cerveri I, Bugiani M, Ferrari M, Verlato G. An undetected burden of asthina in Italy: the relationship between clinical and epidemiological diagnosis of asthma. Eur Respir J 1998; 11: 599 \pm 605 .

[19] Ponsonby A-L, Couper D, Dwyer T, Carmichael A, Wood-Baker R. Exercise-induced bronchial hyperresponsiveness and parental ISAAC questionnaire responses. Eur Respir J 1996; 9: 1356 \pm 1362 .

[20] Singh AB, Kumar P, 2002. Common environmental allergens causing respiratory allergy in India. Indian J Paediatr.69:245-50.11. 